\title{
Intraoperative Complications of High Volume Sutureless Cataract Surgery in Nepal: A Prospective Study
}

\section{Limbu B, ${ }^{1}$ Jha $\mathrm{HC}^{2}$}

\author{
${ }^{1}$ Tilganga Institute of Ophthalmology \\ Gaushala, Kathmandu, Nepal \\ ${ }^{2}$ Shree Janaki Eye Hospital

\section{Corresponding author} \\ Ben Limbu \\ Tilganga Institute of Ophthalmology \\ Gaushala, Kathmandu, Nepal
}

Email: ben_limbu007@yahoo.com

\section{Citation}

Limbu B, Jha HC. Intraoperative Complications of High Volume Sutureless cataract surgery in Nepal: A Prospective Study. Kathmandu Univ Med J 2014:47(3):194-7.

\section{ABSTRACT}

\section{Background}

With high backlog of cataract blindness in the developing countries sutureless high volume cataract surgery is preferred surgical technique.

\section{Objective}

To report the intraoperative complications of high volume sutureless cataract surgery at secondary level eye care centre of Nepal.

\section{Method}

This prospective study consisting 1087 eyes that underwent manual small incision cataract surgery from $2^{\text {nd }}$ to $28^{\text {th }}$ December 2007 at Shree Janaki Eye Hospital, Janakpur, Nepal and operated by a single eye surgeon. Preoperative and postoperative ocular findings together with intraoperative complications were carefully noted in every individual case. At post operative day one each patient was examined including uncorrected visual acuity and post operative complications which were subsequently recorded in Performa. Data were analysed using SPSS 11.5.

\section{Result}

Sixty-three eyes (5.8\%) of 1087 eyes developed intraoperative complications. Out of 63 eyes that had intra operative complications, posterior capsular rupture were seen in $42(3.9 \%)$, sclera corneal tunnel suturing in 12 eyes (1.1\%), iridodialysis 5 eyes $(0.5 \%)$ and Descemet stripping in 4 eyes $(0.4 \%) .62 .1 \%$ of patients attained uncorrected visual acuity $6 / 18$ or better and in $91.7 \%$ of eyes, there were no post operative complications.

\section{Conclusion}

High volume suture less cataract surgery is safe surgery and should be continue in developing countries to achieve the goal of vision 2020, where there is huge backlog of cataract blindness.

\section{KEY WORDS}

High volume suture less cataract surgery, intraoperative complications, Nepal 


\section{INTRODUCTION}

Cataract is a major cause of visual blindness globally with highest burden in developing countries especially in South East Asia. ${ }^{1}$ Cataract has been reported a major cause of blindness in Nepal accounting for $74.2 \%{ }^{2}$ Similar report (74.62\%) has been presented from India. ${ }^{3}$ Manual small incision cataract surgery (MSICS) is a novel approach to address this massive problem of cataract blindness as it is faster and cheaper technology for visual rehabilitation. ${ }^{4-10}$ Shree Janaki Eye Hospital is located at Janakpur close to Indian border imparting it's services to patients around the Terai belt of Nepal and India. This hospital is a very busy secondary level eye care facility performing 13000 cataract surgeries each year (Unpublished data, Administrator, Shree Janaki Eye Hospital, Janakpur) with its limited manpower and instruments. Majority of patients visiting the hospital for cataract surgery travel considerable distance and usually cannot return for routine post operative examinations. A single eye surgeon performs high volume unplanned sutureless cataract surgery each day. Considering these facts, this prospective study was carried out to report the intra operative complications of high volume sutureless cataract surgery. To our knowledge there is no literature in the past describing exclusively intra operative complications of high volume sutureless cataract surgery from Nepal.

\section{METHODS}

A prospective hospital based study was carried out at Shree Janaki Eye Hospital during the period of $2^{\text {nd }}$ to $28^{\text {th }}$ December 2007. All the consecutive patients who underwent MSICS during the period were enrolled in the study after a written consent was obtained. A Performa was designed to fill the data of patients and attached to the surgical card before surgery. Patients were admitted one day prior or on the same day of surgery and discharged on the next day of surgery. All the surgery were performed by single senior ophthalmologist who was the only the eye surgeon during the study period. All intra operative complications were carefully observed and filled in the Performa.

The surgery was performed using superior approach under retro bulbar anaesthesia. After a limited peritomy and light wet field cautery, 6 to $7 \mathrm{~mm}$ scleral tunnel incision was prepared with a diamond Crescent knife starting 1.5 to $2.0 \mathrm{~mm}$ behind the limbus and 1.0 to $1.5 \mathrm{~mm}$ into clear cornea. Anterior chamber was entered with $3.0 \mathrm{~mm}$ keratome and linear capsulotomy performed with bent 30 $\mathrm{G}$ needle, after which forceful hydro dissection is done to mobilize the nucleus. Then the nucleus is slightly lifted at the side of the tunnel. After opening the entire internal lip of the tunnel incision, fishhook is used for nucleus extraction from the capsular bag as described by Hennig A. ${ }^{11} \mathrm{~A}$ single-piece polymethylmethacrylate intraocular lens (PMMA IOL) was inserted into the capsular bag after all cortical material was removed. The anterior capsular flap was then truncated with Vannus scissor and removed with the aspirating Simcoe cannula. Finally, a water tight wound was confirmed by re-inflating the eye with balanced salt solution. No sutures were placed, and the conjunctiva was apposed with cautery in uncomplicated surgery. Finally, sub conjunctival injection with combination of Gentamycin \& Dexamethasone was given followed by padding after removal of drape. All patients who had vitreous loss during surgery underwent open sky vitrectomy with Vannas scissor due to lack of vitrectomy machine. In this study, intra operative complications were considered from beginning of conjunctival peritomy till eye was padded.

All patients received the same postoperative topical combination of Chloramphenicol (1\%) and dexamethasone $0.1 \%$ eye drops every two hourly from day one of operation till day eight in all uncomplicated cases. The dose of topical medicine was decreased to four times a day till fourth week after surgery. Patients were advised to taper the medicine gradually after fourth week for a period of another two weeks.

Postoperatively, all patients were examined on the $1^{\text {st }}$ postoperative day under slit lamp after removal of eye pad and eye dressing. The intra operative and postoperative complications were graded according to Oxford Cataract Treatment and Evaluation Team (OCTET) classification. ${ }^{12}$ According to OCTET, Grade I were trivial complications that may have needed medical therapy, but were not likely to result in a marked drop in visual acuity. Grade II were intermediate complications that needed medical therapy, and would have resulted in a marked drop in visual acuity if left untreated. Grade III were serious complications that would have needed immediate medical or surgical intervention to prevent gross visual loss. Levels of uncorrected visual acuity (UCVA) after cataract surgery were categorized using the WHO guidelines that is, good outcome was defined as $6 / 6-6 / 18$, borderline outcome as $6 / 24-6 / 60$, and poor outcome as $6 / 60$. Statistical analysis was performed using SPSS 11.5 .

\section{RESULTS}

Within the 24 consecutive days, a single surgeon performed 1087 cataract surgery ( $3-6$ operating hours per day). Mean age of patients in the series was 59.94 years (SD 10.93) with age range from 6 - 95 years. Demographic profiles of the participants are listed in table 1.

Large proportion of eyes 508 (46.7\%) out of 1087 , had pre operative visual acuity of counting finger from half meter to perception of light. Seven (0.7\%) patients had advanced primary open glaucoma, six patients had congenital cataract, eight patients had complicated cataract (Five had traumatic cataract and 3 had post uveitis cataract). All the rest were age related cataract. Among 1087 eyes, 616 eyes were of mature cataract, 409 eyes were immature cataract and 62 eyes were Morgagnian cataract. The fellow eye of 
Table 1. Demographic profiles of participants

\begin{tabular}{lcc|}
\hline Characteristics & Frequency $(\mathbf{n})$ & Percentage (\%) \\
\hline Age & & \\
\hline 15 Years or Less & 7 & .6 \\
\hline$>15$ to 40 Years & 58 & 5.3 \\
\hline$>40$ to 65 Years & 787 & 72.4 \\
$>65$ years & 235 & 21.6 \\
\hline Sex & & \\
\hline Female & 605 & 55.7 \\
\hline Male & 482 & 44.3 \\
\hline Address & & \\
\hline Nepal & 561 & 51.6 \\
\hline India & 526 & 48.4 \\
\hline Operated eye & & \\
\hline Right eye & 604 & 55.6 \\
\hline Left eye & 483 & 44.4 \\
\hline
\end{tabular}

802 patients (73.8\%) had cataract, 219 patients (20.1\%) had psuedophakia, 27 patients (2.5\%) had normal phakic lens, 24 patients $(2.2 \%)$ had incurable blindness and 15 patients (1.4\%) had aphakia. Distributions of preoperative visual acuity in operated eyes and fellow eyes are listed in table 2.

Table 2. Distributions of preoperative visual acuity in operated eyes and fellow eyes

\begin{tabular}{lcc}
\hline UCVA Visual acuity & $\begin{array}{c}\text { Pre operative } \\
\text { UCVA }\end{array}$ & $\begin{array}{c}\text { UCVA } \\
\text { in fellow eyes }\end{array}$ \\
\hline $6 / 18$ or Better & $8(0.7 \%)$ & $195(17.9 \%)$ \\
\hline$<6 / 18-6 / 60$ & $51(4.7 \%)$ & $365(33.6 \%)$ \\
\hline$<6 / 60-3 / 60$ & $264(24.3 \%)$ & $202(18.6 \%)$ \\
\hline$<3 / 60-$ Perception of light (PL PR) & $764(70.3 \%)$ & $301(27.7 \%)$ \\
\hline No Perception of Light (NPL) & 0 & $24(2.2 \%)$ \\
\hline
\end{tabular}

\section{Intra operative complications:}

Out of 1087 eyes, intraoperative complications were absent in 1024 eyes (94.2\%). Among 63 eyes (5.8\%) where intraoperative complications noted, majority were posterior capsular rupture 42 eyes (3.9\%). Large number of eyes with posterior capsular rupture received posterior chamber intraocular lens (28/42). Other intra operative complications included sclerotunnel suture (1.1\%), descemet stripping (0.4\%) and iridodialysis (0.5\%). A full list of complications is supplied in table 3 .

\section{Post operative visual acuity}

Six hundred and seventy five eyes (62.1\%) out of 1087 attained post operative uncorrected visual acuity (UCVA) of $6 / 18$ or better. Of the total patient population, $27.2 \%$ had a postoperative uncorrected visual acuity of between $6 / 18$ $-6 / 60$ and $10.7 \%$ had vision below $6 / 60$. A full summary of the postoperative visual acuity can be found in table 4. Subsequently we found six eyes of advanced macular degeneration, three eyes of partial optic atrophy, two eyes of diabetic macular oedema and one eye of macular hole was established after removal of mature cataract on fundus evaluation.
Table 3. Distributions of intra operative complications

\begin{tabular}{|lll|}
\hline $\begin{array}{l}\text { Intra operative complications } \\
\text { Posterior capsule rupture + }\end{array}$ & Frequency (n) & Percentage (\%) \\
Vitreous loss & & \\
\hline PC IOL & 25 & 2.3 \\
\hline AC IOL & 10 & .9 \\
\hline No IOL & 1 & .1 \\
\hline IOL drop + AC IOL & 3 & .3 \\
\hline PCR + PC IOL (No vitreous loss) & 3 & .3 \\
\hline Sclerotunnel suture & 12 & 1.1 \\
\hline Descemet Stripping & 4 & .4 \\
\hline Iridodialysis & 5 & .5 \\
\hline Total & $63 / 1087$ & $5.8 \%$ \\
\hline
\end{tabular}

Table 4. Uncorrected post operative visual acuity of participants at day 1

\begin{tabular}{lll|}
\hline Visual Acuity & Frequency (n) & Percentage (\%) \\
\hline $6 / 18$ or Better (Good) & 675 & 62.1 \\
\hline$<6 / 18-6 / 60$ (Borderline) & 296 & 27.2 \\
$<6 / 60$ (Poor) & 116 & 10.7 \\
\hline Total & 1087 & 100.0
\end{tabular}

\section{Post operative complications}

The postoperative period was uneventful in 997 eyes (91.7\%) of 1087 eyes. The post operative complications included corneal oedema (6.2\%), hyphema (0.9\%), retained cortex at visual axis $(0.4 \%)$, abnormally increased anterior chamber cells $(0.4 \%)$, vitreous present in anterior chamber $(0.4 \%)$ and a shallow anterior chamber $(0.2 \%)$. Of the eyes with complications, nine $(0.9 \%)$ required a second operation. These were the four eyes with retained cortex at the visual axis, three eyes with hyphema $>2 / 3$ of the anterior chamber and two eyes for a shallow anterior chamber. Details of postoperative complications are given in table 5 .

Table 5. Distributions of post operative complications

\begin{tabular}{lll} 
Complications & Frequency (\%) & OCTET Grading* \\
\hline Visual significant corneal edema & $64(5.9)$ & II \\
Corneal edema with raised IOP & $3(0.3)$ & II \\
Hyphema < 1/3 AC & $6(0.6)$ & I \\
$\begin{array}{l}\text { Hyphema > 2/3 AC to Total } \\
\text { Hyphema }\end{array}$ & $3(0.3)$ & III \\
Retained Cortex at visual axis & $4(0.4)$ & III \\
Shallow AC & $2(0.2)$ & III \\
AC Cells > 50 cells/HPF & $4(0.4)$ & II \\
Vitreous in AC not touching & $4(0.4)$ & I \\
cornea or at incision & & \\
Total & $90(9.3 \%)$ &
\end{tabular}

\section{DISCUSSION}

Manual small incision cataract surgery is faster, cheaper and effective technique to tackle a huge backlog of cataract for developing countries in compare to instrumental 
phacoemulsification. . $^{5,13}$

A single eye surgeon performed 1087 cataract surgeries in 24 consecutive days with operating time of $3-6$ hours a day. Among these participants, preoperative presenting visual acuity of $<3 / 60$ was present in large proportion (764 eyes, $70.3 \%$ ) of operated eyes and fellow eyes (301 eyes, $27.7 \%$ ) which is similar to results reported by previous literatures. $^{7-9}$

Out of 1087 eyes, 63 eyes (5.8\%) had intraoperative complications, commonest one being the posterior capsular rupture in 42 eyes (3.9\%). These findings are better than the results of other studies. ${ }^{5,8,14,15}$ Even though, Venkatesh et al reported less intraoperative complications (1.9\%) than our study, surprisingly their post operative complications rate was $11 \%$ which is more than our study results. ${ }^{9}$ Posterior capsular rupture in 42 eyes (3.9\%) is comparable to study result of instrumental phacoemulsification. ${ }^{5}$ Our study finding of posterior capsular rupture with vitreous loss rate in 39 eyes (3.6\%) is higher than other study results. ${ }^{7,9}$ Higher vitreous loss rate in this study may be because we included all patients regardless of their aetiology for cataract and co existing ocular pathology.

Post operative UCVA of $6 / 18$ or better at discharge was present in large proportion of patients 675 (62.1\%). This results are favourable than the finding of other study. ${ }^{5,7,9,15}$ Considering pre operative presenting corrected visual acuity of $<6 / 60$ in $94.6 \%$, there was significant improvement of UCVA at discharge, $6 / 60$ or better in $89.3 \%$. This result suggests large proportion of participants were benefited with surgery. Hennig A et al reported post operative UCVA $6 / 18$ or better at discharge in $384 / 500$ cases $(76.8 \%$ ) which is better than our study which may be because they have excluded the patients who had co existing eye disease that may adversely affect the visual outcome of cataract surgery. ${ }^{8}$

Gogate PM et al, Venkatesh et al and Hennig A et al reported post operative complications rate as $12.6 \%, 9.3 \%$ and $6.2 \%$ respectively. ${ }^{5,9,11}$ Postoperative complications in our study were seen in 90 eyes (9.3\%) of 1087 eyes. Most frequent postoperative complications observed in this study were visually significant corneal oedema. High number of corneal oedema may be because of mature cataract together with inadequate uses of viscoelastic during the surgery.

\section{CONCLUSION}

This study results shows that relatively safe cataract surgery, 93.2\% without intraoperative complications, $62.1 \%$ UCVA at discharge $6 / 18$ or better and $91.7 \%$ without postoperative complications can be attained in a high volume sutureless cataract surgery. These results have significant implications to the developing countries because the principal solution to the backlog of cataract blind is performing cataract operations on a large scale. So, we recommend continuation of high volume sutureless cataract surgery (MSICS) as a standard procedure in order to achieve the goal of vision 2020 in developing countries.

\section{REFERENCES}

1. Thylefors B, Negrel AD, Pararajasegram R, Dadzie KY. Global data on blindness. Bull World Health Organ 1995;73(1):115-21.

2. Sapkota YD, Pokharel GP, Nirmalan PK, Dulal S, Maharjan M, Paul PG et al. Prevalence of blindness and cataract surgery in Gandaki Zone, Nepal. Br J Ophthalmol 2006;90:411-416.

3. Vijaya L, George R, Arvind H, Baskaran M, Raju P, Ramesh SV et al. Prevalence and causes of blindness in the rural population of the Chennai Glaucoma Study. Br J Ophthalmol 2006;90:407-10.

4. Ruit S, Paudyal G, Gurung R, Tabin G, Moran D, Brian G. An innovation in developing world cataract surgery: Sutureless extracapsular cataract extraction with intraocular lens implantation. Clin Exp Ophthalmol 2000;28:274-9.

5. Gogate PM, Kulkarni SR, Krishnaiah S, Deshpande RD, JoshiSA, Palimkar A et al. Safety and efficacy of phacoemulsification compared with manual small-incision cataract surgery by a randomized controlled clinical trial: six-week results. Ophthalmology 2005;112:869-874.

6. Tabin GC, Chen M and Espandar L. Cataract surgery for the developing world. Current Opinion in Ophthalmology 2008,19:55-9.

7. Paul JG, Ching A. Small-incision manual extracapsular cataract surgery in Ghana, West Africa. Journ cataract and refractive surgery 2003;23:57- 64 .

8. Hennig A, Kumar J, Yorston D, Foster A. Sutureless cataract surgery with nucleus extraction: Outcome of a prospective study in Nepal. $\mathrm{Br}$ J Ophthalmol 2003;87:266-70.
9. Venkatesh R, Muralikrishnan R, Balent LC, Prakash SK,Prajna NV. Outcomes of high volume cataract surgeries in a developing country. Br J Ophthalmol 2005;89:1079-83.

10. Balent LC, Narendrum K, Patel S, Kar S, Patterson DA. High volume sutureless intraocular lens surgery in a rural eye camp in India. Ophthalmic Surg Lasers 2001 Nov-Dec;32(6):446-55.

11. Hennig A. Sutureless cataract surgery with nucleus extraction fishhook technique. In: Garg A, editor. Clinical practice in small incision cataract surgery (Phaco Manual)". New Delhi: Jaypee Medical Publishers; 2004:417-21.

12. Oxford cataract Treatment and Evaluation Team.Use of grading system in evaluation of complications in a randomized controlled trial. Br J Ophthalmol 1986;70:411-4.

13. Ruit S, Tabin GC, Chang D, Bajracharya L, Kline DC, Richheimer W, et al. A prospective randomized clinical trial of phacoemulsification vs manual sutureless small-incision extracapsular cataract surgery in Nepal. Am J Ophthalmol 2007;143:32-8.

14. Gao $\mathrm{Y}$, Chen T, Zhao S. An analysis of posterior capsular rupture in cataract surgery. Zhonghua Yan Ke Za Zhi 1996 May;32(3):200-2.

15. Gogate PM, Deshpande M, Wormald RP, Deshpande R, Kulkarni SR. Extracapsular cataract surgery compared with manual small incision cataract surgery in community eye care setting in western India: a randomised controlled trial. Br J Ophthalmol 2003;87:667-72. 